\title{
La religión neo-colonial como la forma actual de la economía política de la moral
}

\author{
Adrián Scribano*
}

\section{Resumen}

En este trabajo pretendemos exponer brevemente cómo es posible comprender lo que hemos denominado religión neocolonial en tanto rasgo central de los procesos de expansión del capital a escala planetaria y el surgimiento de prácticas intersticiales en tanto formas sociales que desmienten el régimen de verdad de la economía política de la moral. Para lograr el objetivo enunciado hemos seleccionado la siguiente estrategia de argumentación: a) explicitamos brevemente algunos rasgos del capitalismo como religión, b) exponemos algunas de las conclusiones de nuestras indagaciones sobre como caracterizar la situación actual del capitalismo, c) desarrollamos los aspectos centrales de lo que consideramos la religión neo-colonial vigente, d) esquematizamos las prácticas intersticiales que emergen de la descripción realizada y e) concluimos con una sintética referencia a lo que consideramos los motivos por los cuales esta temática deviene de fundamental importancia para el capitalismo en la actualidad.

\section{Palabras clave}

Religión - Capitalismo - Prácticas intersticiales.

\footnotetext{
* Investigador del CONICET, IIGG-FSC-UBA; Director del CIES www.estudiosociologicos.com.ar
} 


\section{Abstract}

In this paper we briefly outline as possible to understand what we call neo-colonial religion as central feature of the process of expansion of capital on a global scale and the emergence of interstitial practices in both social forms that belie the truth of the regime political economy of morality.

To achieve the stated objective we have selected the following strategy of argument: a) we explicit briefly some features of capitalism as religion, b) present some of the findings of our research on how to characterize the current state of capitalism, c) develop the core aspects of what we consider religion neocolonial, d) schematize interstitial practices that emerge from the description given, and e) synthetic conclude with a reference to what we consider the reasons why this issue becomes of fundamental importance to capitalism in the today.

\section{Keywords}

Religion - capitalism - interstitial practices.

\section{Introducción}

Las Ciencias Sociales en general y la sociología en particular desde sus propios inicios han indagado y reflexionado sistemáticamente sobre las conexiones entre religión, capitalismo y los procesos de estructuración social.

Unas de las aristas de las aludidas conexiones son el plexo relacional entre creencias, formas de vida y coordinación de la acción especialmente referida a las continuidades y discontinuidades entre acción individual y prácticas colectivas. En este sentido, las investigaciones se multiplican (y multiplicaron) sea desde la temática de la modernidad, la sociedad industrial o del espíritu del capitalismo.

En dicho contexto se han forjado una serie de enfoques teóricos, culturas de investigación o paradigmas con la intensión de someter a análisis y dar cuenta de un interrogante devenido tópico central de la ciencias sociales: ¿qué es lo que mantiene unidos, articulados o coordinados a los sujetos en una estructura social que parece implicar una disolución constante de los lazos sociales?

En las últimas décadas del siglo pasado, un fenómeno "comenzó" a ser debatido y estudiado con diversas denominaciones: globalización, planetarización o expansión a escala global del capitalismo.

Todas estas indagaciones volvieron a re-tematizar las nuevas/viejas fisonomías de las interacciones sociales en términos de creencias e identidades donde se prestaba atención a sus rasgos generales y específicos inscriptos en la trama local/global. En 
dicho marco la pregunta arriba formulada quedaba en pie y renovaba su interés y centralidad.

Paralelamente, en esas mismas décadas se constituyó un movimiento intelectual y también un "paradigma" que, entre sus muchas expresiones, se denominó postcolonialismo, que retomando una antigua desconfianza a la razón geopolíticamente condicionada extendió el debate sobre las consecuencias de la expansión a escala planetaria del capitalismo hasta el corazón de las violencias epistémicas y simbólicas que anidan en la visión estándar de las ciencias sociales sobre las creencias, saberes y (des)localizaciones.

Si se ponen en relación estas tres aristas enunciadas, esto es, la relación entre creencias, formas de vida y coordinación de la acción; expansión a escala global del capitalismo, creencias e identidades y creencias, saberes y (des)localizaciones; es fácil advertir la permanencia/persistencia de un rasgo transversal que puede ser apreciado: la dialéctica entre religión/creencias/expansión del capitalismo.

En los últimos diez años hemos investigado sistemáticamente cómo las formas globales de expansión del capital que se han instanciado en el sur global implican transformaciones fundamentales en su economía política de la moral. Desde diversas perspectivas y ejes temáticos hemos intentado comprender las huellas que dejan nuestras investigaciones empíricas para pensar y re-pensar las políticas de los cuerpos y las emociones en condiciones de (neo-)colonialidad. ${ }^{1}$

En este trabajo pretendemos exponer brevemente cómo es posible comprender lo que hemos denominado religión neo-colonial en tanto rasgo central de los procesos de expansión del capital a escala planetaria y el surgimiento de prácticas intersticiales en tanto formas sociales que desmienten el régimen de verdad de la economía política de la moral.

Para lograr el objetivo enunciado hemos seleccionado la siguiente estrategia de argumentación: a) explicitamos brevemente algunos rasgos del capitalismo como religión, b) exponemos algunas de las conclusiones de nuestras indagaciones sobre como caracterizar la situación actual del capitalismo, c) desarrollamos los aspectos centrales de lo que consideramos la religión neo-colonial vigente, d) esquematizamos las prácticas intersticiales que emergen de la descripción realizada y e) concluimos con una sintética referencia a lo que consideramos los motivos por los cuales esta temática deviene de fundamental importancia para el capitalismo en la actualidad.

Se finaliza abogando por la urgencia en reparar en la importancia de la estructura sacrificial del sistema capitalista en el actual contexto de su re-estructuración y la necesidad de indagar sus metamorfosis.

Como punto de partida epistemológico y teórico es necesario aclarar que si bien la perspectiva aquí utilizada hunde sus raíces en algunas de las más prestigiosas

\footnotetext{
1 Para algunos de los trabajos más recientes CFR Scribano 2010a, 2012,c, 2012b, 2012a, 2013c 2013b.
} 
tradiciones de las ciencias sociales, está inspirada por el convencimiento de la urgencia y necesidad de elaborar aproximaciones conceptuales desde una mirad posindependentista. Sobre esto último hemos expuesto nuestro punto de vista en diversos trabajos, desarrollo que por cuestiones de espacio y objetivos específicos del presente artículo no podemos realizar aquí.

\section{El capitalismo como religión ${ }^{2}$}

Un punto controversial sobre los resultados de nuestras indagaciones lo suele constituir el porqué designar como religión a un fenómeno captado en los procesos de estructuración social.

El presente apartado busca de un modo muy esquemático hacer evidente en qué términos pueden ser relacionados religión y capitalismo.

Las creencias religiosas de los hombres, las maneras como estos se han dado para producirlas y reproducirlas, las consecuencias de esto en las formaciones sociales siempre han tenido una importancia crucial en la estructuración de las sociedades.

Las relaciones sociales capitalistas implican un proceso permanente de elaboración de creencias encargadas de explicar el mundo y dar cuenta de las prácticas de los sujetos que lo construyen.

Nuestras indagaciones están orientadas a mostrar el proceso aludido desde la convergencia entre los estudios sociales sobre las emociones y los cuerpos, los estudios sobre acción colectiva y conflicto social y la crítica ideológica.

En el contexto aludido pretendemos bosquejar una respuesta a la pregunta ¿cuáles son las relaciones entre Capitalismo y Religión? desde una presentación sumaria de las ideas de Durkheim, Weber y Marx al respecto ${ }^{3}$.

Unas de las preocupaciones centrales de Emilie Durkheim fue el explicar qué era lo que mantenía unidad a la sociedad tras el impacto disolvente del estado moderno y el industrialismo en las formas "tradicionales" de vida. Unas de las vías que siguió para responder este interrogante fue el estudio de las maneras como las sociedades elaboraban lazos colectivos fundados en una moral compartida.

Durkheim pensó en los cimientos y cementos de la sociedad en tanto suturas del quiebre y las fallas producidas por la sociedad industrial indagando las formas elementales de la vida religiosa que habían cumplido dicha función.

También indagó los modos humanos de reemplazo de la palabra divina como elemento vinculante entre los hombres en sus formas de tensión entre normas sociales, creencias colectivas y derecho positivo.

\footnotetext{
${ }^{2}$ Como horizonte de comprensión de algunos rastros seguidos para entender el capitalismo como religión CFR Bataille, G. 1991; Baudrillard, J. 1991 y especialmente Benjamin, W. 1991

${ }^{3}$ Como referencias generales a las ideas aquí expuestas sobre los tres autores CFR Marx, C. 2001, 1974; Durkheim, E. 1983, 1972 y Weber, M. 1963, 1990.
} 
Es en dicha dirección que observó cómo se producía la transformación de las formas elementales de la vida religiosa en representaciones colectivas re-normativisadas y "traducidas" a lenguaje desacralizado. En definitiva, procuró para la sociedad una moral humana que "reemplazará" la función social de la religión de mantener unidos a los sujetos y proveer "esquemas mentales" que posibilitaran la explicación del mundo, de lo bajo y lo alto, de lo digno y lo indigno, etc.

Por otro lado, existe en Max Weber un conjunto de pistas para comprender cómo el proceso de racionalización del mundo implica el progresivo desencanto en términos de la expulsión de las formas de magia social, instalando a la racionalidad instrumental que guía a través del cálculo medio/fines las estructuras del deber hacer en la sociedad capitalista.

Para Weber los continuos y sistemáticos procesos de racionalización a los que fueron sometidas las imágenes religiosas del mundo, por un lado, y los procesos de transformación capilares e institucionales de las creencias en Occidente, por otro lado, coadyuvaron a formar la "moral" capitalista.

Una de las bases de dicha moral es posible encontrarla en las pautas de interacción que contradictoria pero sistémicamente van dando forma al espíritu del capitalismo en su expresión de máximas de vida: ahorro ascético y despilfarro.

Weber exploró el "espíritu" de capitalismo como mecanismo de coordinación de la acción que al desacralizarse adquiere y se reviste del carácter de imperativo moral. Por esta vía el lucro y la utilidad quedan soldados a dos componentes elementales del mercado: la escasez y las necesidades, que debían ser afrontados desde las distancias/proximidades entre multiplicidad de fines e insuficiencia de medios.

La explicación del capitalismo implica para Weber el análisis sistemático de cómo los valores de la vida económica y las consecuencias de la expansión de la ciencia moderna como criterio de verdad tramaron un conjunto de creencias con pretensiones de universalidad.

Carlos Marx se percató del sesgo religioso que adquiere el mundo de las cosas en el contexto de mercantilización de la vida que el capitalismo implicaba. En su búsqueda de comprensión del capitalismo exploró los orígenes de la economía política en tanto discurso normativo que ponía en palabras las prácticas de expropiación que se efectivizaban en el auge de la revolución industrial.

Para Marx una de las claves del entero edificio del capitalismo lo constituye el proceso por el cual aparece el fetichismo de la mercancía como el resultado de las acciones por las cuales las cosas/mercancías comienzan a ser el centro de la vida de los hombres. Las reglas del mundo de las cosas pasan a ser reglas del mundo del hombre, entregados estos al poder del fetiche que interpela su vida e identidad como productores/consumidores.

La autonomía de los hombres deviene heteronimia respecto de las mercancías, revestidas estas de poderes fantasiosos y cualidades mágicas que provocan dos 
procesos paralelos: la "naturalización" del obrero como mercancía en tanto medio y forma de vida y la entronización de la mercancía como "patrón" de vida.

Es así como en Marx mercancía, fetiche y fantasías constituyen los componentes del neblinoso mundo de la religión del capitalismo, donde alienación (como pérdida de autonomía) y adoración de la mercancía (como culto al lucro) son partes indisolubles de un régimen social de las cosas.

El capitalismo en tanto generador de representaciones colectivas cuya función es brindar una cemento que re-liga sus efectos de individuación/fragmentación, la expansión de la racionalidad instrumental como lógica de la interacción social en tanto consecuencia de la desacralización/desencantamiento de las éticas religiosas y la constitución de una economía política de la moral basada en creencias compartidas sobre las reglas de conducta recortadas al talle de los principios elementales del mercado como mecanismo explicativo de la conducta de los hombres posibilitan entender a su sociabilidad como una religión.

Es así como se puede entender que el capitalismo en tanto religión provea de imágenes elementales de cohesión, promueva una forma de articulación de la acción y estructure un conjunto de creencias sobre el origen, desarrollo y finalidad de ambas.

Es en cuanto a esto que las estructuras de la economía política de la moral constituyen hoy una religión secular de todos los sujetos que viven en el sistema capitalista y en especial de los expulsados y desamparados en el Sur Global.

Frente a los procesos de expulsión y expropiación excedentaria, el culto a la mercancía vuelta fetiche opera como momentos que re-une, re-liga y re-arma lo que en dichos procesos hay de desconexión y pérdida. Ahora bien, estos momentos se elaboran sobre el terreno de un proceso de expansión del capital a escala planetaria cuyos resultados implican justamente su inversión: vacío, pérdida y descomposición. Para comprender las contradicciones que anidan en dichos resultados y cómo se relacionan con el capitalismo como religión, es menester exponer, al menos esquemáticamente, los rasgos centrales de la aludida expansión del capital.

\section{Expansión del capital: depredación, regulación de las sensaciones y represión ${ }^{4}$}

helicoidalmente la situación actual del capitalismo a escala planetaria y regional: las prácticas de depredación de los bienes comunes, la elaboración de los mecanismos de

soportabilidad social y los dispositivos de regulación de las sensaciones y la redefiniciones de la represión-militarización de las sociedades.

En primer lugar, en sus distintas fases imperiales el capital siempre ha tenido como objetivos garantizar, a largo plazo, las condiciones de su reproducción a escala

\footnotetext{
${ }^{4}$ Para el desarrollo de estas categorías CFR Scribano, A. 2012a Teorías sociales del Sur: Una mirada postindependentista.
} 
sistémica. En la actualidad la concentración monopólica del capital deviene en un aparato extractivo del aire del presente para gestionar el aire del futuro. La fuerza viva del capital, que son los seres humanos devenidos meros "cuerpos-en-trabajo" para el disfrute de unos pocos bajo la fantasía del deseo de todos, necesita garantizar la máxima tasa de apropiación ecológica para poder conservar a mediano plazo la estructura (cambiante) de las clases dominantes. En tal sentido, la ubicación, manejo y depuración de las fuentes de agua a nivel mundial es otra de las aristas de la extracción depredadora del afianzamiento de su metamorfosis en condiciones de desigualdad. Sin agua no hay cuerpos ni sistemas de reproducción alimentaria; la biogenética resguarda el equilibrio necesario y suficiente de la apropiación del futuro. La consolidación de la extracción de aire y agua (en contextos de elaboración, almacenamiento y distribución a escala planetaria) se funda en la necesidad de apropiación de tierras productoras y contenedoras de esos dos componentes básicos de la vida. Selvas, bosques y campos deben ser asegurados por las alianzas de las fracciones de las clases dominantes nacionales a través de garantías de los estados nacionales de apropiación privada, privatizadas y globalizadas de las corporaciones internacionales del gerenciamiento ecológico.

En la misma dirección, la otra arista de la maquinaria extractiva es la energía en todas sus variantes, desde petróleo a la energía corporal socialmente disponible y consumible. Más allá del fatal proceso de extinción de estas energías básicas para el capital, su regulación en la actualidad constituye el centro de su reproducción a corto plazo. Por lo tanto, una crítica de la economía eco-política es un paso importante e insustituible para entender la expansión imperialista. Un elemento constituyente de una crítica así entendida es hacer visible cómo se cruzan, revelan y escriben las políticas de las energías corporales. Las tribulaciones que entumecen cuerpos a través del dolor social son una de las vías privilegiadas para la apropiación desigual de las aludidas energías corporales.

En segundo lugar, para la fase actual del imperialismo es indispensable la producción y manejo de dispositivos de regulación de las expectativas y evitación del conflicto social. Dicho manejo se garantiza por los mecanismos de soportabilidad social y los dispositivos de regulación de las sensaciones, sobre los que volveremos más adelante, por ser los componentes claves de la religión neo-colonial.

En tercer lugar, la expansión imperial contempla de modos diversos la militarización planetaria. No pueden mantenerse cantidades equilibradas del funcionamiento del aparato extractivo y de los dispositivos de regulación de las sensaciones sin un aparato represivo, disciplinar y de control mundial que trascienda la mera ocupación militar. La represión global se orienta a sostener el estado de vigilancia neo-colonial, dada la reorganización paradójica de las composiciones, posiciones y condiciones de clases en espacio-tiempos complejos con movimientos centrífugos (que alejan del centro) y centrípetos (que atraen hacia el centro) de las diversas maneras de resistir la 
expropiación energética y la regulación de las sensaciones. Además, la militarización potencial de todo conflicto en los sistemas dependientes obedece geopolíticamente a las metamorfosis del capital financiero concentrado, la re-definición de los "patrones de acumulación" corporativa y la fragmentación y unidad de la expropiación.

Así se puede entender, al menos parcialmente, de qué manera la expansión imperial, caracterizada como un aparato extractivo de aire, agua, tierra y energía y como máquina militar represiva, se sostiene y reproduce -entre otros factores- por la producción y manejo de dispositivos de regulación de las sensaciones y mecanismos de soportabilidad social.

Del mismo modo se puede comprender cómo la textura vincular entre particularizaciones, individuaciones y localizaciones de la desigualdades se trama en el actual estado de la expansión del capital como imperialismo, la dependencia y situación colonial. Como hemos sostenido en otro lugar (Scribano 2010):

a) Cuando existen en la tierra grupos sociales que centralizan la capacidad concentrada de imposición de las necesidades, deseos y acciones constituyendo una economía política de la moral que consagra las expropiaciones excedentarias, evitando así toda forma de prácticas autónomas, se está frente a una modalidad de imperialismo.

b) Cuando existe una trama de relaciones ente territorios, naciones y estados que socializa los efectos destructivos de los procesos de acumulación de los activos ambientales, condicionadas (dichas relaciones) por el estado de los campos productivos de alta rentabilidad, estructuradas por medio de la conexiones de las clases dominantes globales, estamos frente a una situación de dependencia.

c) Cuando hay segregación clasista detrás de "murallas" que contienen y reproducen los momentos de expropiación y desposesión consagrados por la racialización existe una experiencia colonial.

En el contexto de lo expuesto es que podemos entender "el colonizar" como un acto que comienza y reproduce en las ciudades (coloniales) con las siguientes características:

Colonizar es ocupar. Desde esa perspectiva, la ciudad evidencia cómo el capitalismo en su fase actual reconfigura su poder en y desde las tramas urbanas segregacionistas y expulsivas.

Colonizar es expropiar. Las ocupaciones clasistas de las ciudades operan como forma de des-posesiones acumulativas de las capacidades para el habitar.

Colonizar es habitar el tiempo-espacio de otro. La vida vivida desde la rostrocidad de un próximo y un ajeno que paraliza de miedo es la marca de los bordes de una ciudad y sus muros mentales.

Colonizar es tener el poder de decidir sobre la vida de los otros. La ciudad neocolonial es la concreción iterativa de las tramas de la imposición de unas voluntades sobre otras en condiciones de total heteronimia. 
Es en este marco de la sujeción colonial donde se inscriben las alteraciones de las diferencias y jerarquías entre sujetos y grupos sociales en el sur global. Las formas elementales de las modulaciones de clase se pluralizan y concentran, se multiplican y agrupan en torno a las dialécticas de lo colonial re-construido como esquema de toda formación social.

En el contexto de la producción y reproducción de la experiencia colonial aludida emerge una manera de soportar y "participar" de ella que con-tiene todos los rasgos de una religión, tal como ya lo hemos expuesto más arriba.

\section{Religión neo-colonial: nuevas trinidades y sus pastorales}

Las diversas facetas del proceso de expansión del capitalismo a escala planetaria han necesitado distintas formas de expresar la economía política de la moral. Desde el despilfarro burgués pasando por el espíritu de ahorro ascético, llegando a la elaboración de la racialidad como parámetro de comportamiento son algunos de los ejemplos de las aludidas transformaciones.

Una de las astucias de la razón colonizadora fue dar por muerta toda religión para que viviera solo la religión moderna y modernizante de la mercancía. Entre las primeras prácticas de adoración se colocó la creencia que sustenta a la acumulación de riquezas como único medio de obtener una vida digna; esta fue acompañada luego por la acumulación de poder y conocimiento como formas sociales que garantizaban la vida plena.

En este contexto la modernidad capitalista inauguraba la curiosa religión que no religa sino individualiza, fragmenta y monologiza las relaciones sociales e instauró un conjunto de "creencias" que debían ser desacralizadas en su reproducción laica del estado burgués.

En las investigaciones empíricas y teóricas que venimos realizando elaboramos una caracterización de lo que hemos dado en llamar la trinidad de la religión neo-colonial, como una lectura del estado actual de constitución de una economía política de la moral. Una religión que tiene sus tablas de la Ley, sus liturgias y pastorales en consonancia con las estructuraciones sociales que implica la actual fase de la expansión imperial.

Una sociología de la sujeción indeterminada involucra la aceptación de que si se pretenden conocer los patrones de dominación vigentes en una sociedad, hay que analizar: cuáles son las distancias que esa misma sociedad impone sobre sus propios cuerpos, de qué manera los marca, y de qué modo se hallan disponibles sus energías sociales. Así, la política de los cuerpos, es decir, las estrategias que una sociedad acepta para dar respuesta a la disponibilidad social de los individuos, es un capítulo, y no el menor, de la estructuración del poder. Dichas estrategias se anudan y son "fortalecidas" 
por las políticas de las emociones tendientes a regular la construcción de la sensibilidad(es) social(es).

\section{a) Dispositivos de regulación de las sensaciones y políticas de las emociones ${ }^{5}$}

Lo que sabemos del mundo lo sabemos por y a través de nuestros cuerpos, lo que hacemos es lo que vemos, lo que vemos es como di-vidimos el mundo. En ese "ahíahora" se instalan los dispositivos de regulación de las sensaciones, mediante los cuales el mundo social es aprehendido y narrado desde la expropiación que le dio origen a la situación de dominación.

Las sensaciones están distribuidas de acuerdo con las formas específicas de capital corporal. El capital corporal son las condiciones de existencia alojadas en el cuerpo individuo, en el cuerpo subjetivo y en el social.

La tensión entre cuerpo individuo, subjetivo y social es una de las claves que permitirán entender las conexiones entre geometrías de los cuerpos y gramáticas de la acción, que son parte de la dominación neo-colonial en los países de América Latina. La tensión aludida cobra mayor sentido si se entrecruza aun más la mirada desde los cuerpos con la visión desde las sensaciones.

Percepciones, sensaciones y emociones constituyen un trípode que permite entender dónde se fundan las sensibilidades. Los agentes sociales conocen el mundo a través de sus cuerpos. Por esta vía un conjunto de impresiones impactan en las formas de "intercambio" con el con-texto socio-ambiental. Dichas impresiones de objetos, fenómenos, procesos y otros agentes estructuran las percepciones que los sujetos acumulan y reproducen. Una percepción desde esta perspectiva constituye un modo naturalizado de organizar el conjunto de impresiones que se dan en un agente.

La vía privilegiada de conexión entre acciones colectivas, fantasmas y fantasías sociales la constituye la aceptación de que el cuerpo es el locus de la conflictividad y el orden. Es el lugar y topos de la conflictividad por donde pasan (buena parte de) las lógicas de los antagonismos contemporáneos. Desde aquí es posible observar la

\footnotetext{
${ }^{5}$ Hemos expuesto las principales líneas de una sociología de los cuerpos y de las emociones en Adrián Scribano (Comp.) "Policromía Corporal. Cuerpos, Grafías y Sociedad". CEA CONICET UNIVERSIDAD NACIONAL DE CORDOBA. UNIVERSIDAD DE GUADALAJARA. Colección Acción Social, Jorge Sarmiento Editor, Universitas, 2007a; Luna, R. y Scribano, A. (Comp.) "Contigo Aprendí... Estudios Sociales de las Emociones" CEA-CONICET-UNC -CUSCH-UdeG 2007b. Scribano, Adrián (Comp.) "Mapeando Interiores. Cuerpo, Conflicto y Sensaciones." Adrián Scribano (Comp.) CEA-CONICET-UNC - Jorge Sarmiento Editor 2007c; Adrián Scribano (Comp). "Geometría del Conflicto: Estudios sobre Acción Colectiva y Conflicto Social". Centro de Estudios Avanzados. UNC. Editorial Universitas. Córdoba. 2005b; Adrián Scribano. "Itinerarios de la Protesta y del Conflicto Social". Centro de Estudios Avanzados. UNC, Instituto Académico Pedagógico de Ciencias Sociales. UNVM. Editorial Copiar. Córdoba. 2005a.
} 
constitución de una economía política de la moral, es decir, unos modos de sensibilidades, prácticas y representaciones que ponen en palabras la dominación. ${ }^{6}$

En este contexto, entenderemos ${ }^{7}$ que los mecanismos de soportabilidad social se estructuran alrededor de un conjunto de prácticas hechas cuerpo que se orientan a la evitación sistemática del conflicto social. Los procesos de desplazamiento de las consecuencias de los antagonismos se presentan como escenarios especulares y desanclados de un espacio-tiempo. Estos permiten la aceptación, por parte del sujeto y la sociedad toda, de que la vida social "se-hace" como un-siempre-así.

Asociado a lo anterior, los dispositivos de regulación de las sensaciones consisten en procesos de selección, clasificación y elaboración de las percepciones socialmente determinadas y distribuidas. La regulación implica la tensión entre sentidos, percepción y sentimientos que organizan las especiales maneras de "apreciarse-en-el-mundo" que las clases y los sujetos poseen.

Las cadenas y esquemas cognitivos-afectivos que conectan (y desconectan) las prácticas sociales en tanto narraciones y visiones del mundo hechas cuerpo constituyen los procesos que aquí se caracterizan como ideológicos. Los mecanismos y dispositivos señalados son un gozne práctico y procedimental donde se instancian los cruces entre emociones, cuerpos y narraciones.

Los mecanismos de soportabilidad social del sistema no actúan ni directa ni explícitamente como "intento de control", ni "profundamente" como procesos de persuasión focal y puntual. Dichos mecanismos operan "casi-desapercibidamente" en la porosidad de la costumbre, en los entramados del común sentido, en las construcciones de las sensaciones que parecen lo más "íntimo" y "único" que todo individuo posee en tanto agente social.

Es justamente en la trama de la configuración de las políticas de los cuerpos y las emociones en la experiencia de colonialidad que abren y despliegan los rasgos de la religión neo-colonial.

\section{b) Constitución trinitaria de la religión del desamparo}

En la actualidad esto se puede observar en el surgimiento de una religión del desamparo neocolonial. Así la política (institucional) debe crear la nueva religión de los países neocoloniales dependientes que reemplace la - ya antigua - trinidad de la "religión industrial" ${ }^{8}$ basada en producción ilimitada, absoluta libertad y felicidad sin

\footnotetext{
${ }^{6}$ Respecto del funcionamiento de algunos de los mecanismos de soportabilidad social y los dispositivos de regulación de las sensaciones, véase Scribano 2007a y 2007b.

7 Los esquemas interpretativos (sensu Giddens) y los habitus (sensu Bourdieu) son dos de las construcciones conceptuales que se aproximan a lo que aquí se entiende por mecanismos de soportabilidad social y dispositivos de regulación de las sensaciones.

8 Nos aproximamos aquí, con varias diferencias, a E. Fromm en su exposición de la idea de religión industrial. CFR Erich Fromm "Avere o essere?" 1977 Modadori Editore. Milano, Italia.
} 
restricciones, por la trinidad de los expulsados compuesta por el consumo mimético, el solidarismo y la resignación. Religión cuya liturgia es la construcción de las fantasías sociales, donde los sueños cumplen una función central en tanto reino de los cielos en la tierra, y la sociodicea de la frustración el papel de narrar y hacer presentesaceptables los fantasmáticos infiernos del pasado vuelto presente continuo.

El consumo mimético implica un conjunto de prácticas conectadas transversalmente que se elaboran en tanto se produce la absorción de propiedades de un objeto como acto de apropiación de él en forma de fantaseo de las cualidades del sujeto portador de dicha acción.

El solidarismo es una relación de sutura de las ausencias inscriptas en un sujeto llevada adelante por otro u otros sujetos que deja indemnes los procesos que causan dichas ausencias.

La resignación es una manera de hacer cuerpo la desfuturización de las expectativas y deseos de un sujeto, construida como efecto de la aceptación de totalidad cerrada de los límites impuestos por sus condiciones materiales de existencia.

Mandatos sociales se instalan como las "nuevas tablas" de la Ley. "Consuma que será feliz..." "Sea bueno alguna vez en el día"... " iResígnese! Porque eso es lo único que Ud. puede hacer"... son algunos de esos mandatos. Desde $-\mathrm{y}$ para - esta trinidad mobesiana entre el consumo, que nos hace ser alguien; entre la solidaridad, que al único que beneficia es al que da, y entre la resignación, que lo único que hace es procurar la aceptación de la limitación de la capacidad de acción, existen consecuencias sociales de multiplicación colectiva que se ritualizan y entrelazan. Es decir, ¿cuáles son las pastorales de esa religión del capitalismo dependiente? Son dos: la sinestesia social y la ataxia social. Desde la primera, las vivencialidades se inscriben en un mundo hipersensibilizado donde las sensaciones se superponen e indiferencian; desde la segunda —en tanto la imposibilidad de coordinar movimientos conjuntos - los sujetos aceptan el atomismo social.

El consumo mimético tiene dos polos entramados: la identificación con el objeto y la heteronomia del disfrute. El "disfrute-desde-el-otro" es uno de los artículos de fe más importantes de la trinidad secular de la religión colonial elaborada sobre la base del solidarismo, la resignación y el consumo mimético. La estructura libidinal del capital se "arma" (en todas su denotaciones) en el trípode de objetificación del otro, mediatización del otro y privatización de las pasiones. Las astucias de una economía política de la moral para individuos convierten a los mismos en objetos, generan la aceptación de sí como dispuesto para el consumo de otro y consagran a los procesos de constitución de objetos como "medidas" de los sujetos. Objetificar es poner en estado de reificación a los seres vivos (en especial a los seres humanos) elaborando su estatus de objetos que implica la cosificación de la vida. En la misma dirección el otro aparece como un medio para un fin: el "otro" es un medio para "mi" goce. Las cualidades del objeto que vuelto "simplemente" una cosa que pueda ser comprado, 
vendido y acumulado se traspasa al que tiene la potencia de comprar, vender y acumular cualquier objeto. Las prestaciones de disfrute del otro como objeto son constitutivas de las vías posibles para un "mi", desanclado de todo otro tipo de relación que no sea la mercantil. Es en este contexto donde la condición sine qua non del capitalismo hace su aparición: privatizar las pasiones para hacer del mundo de los hombres un mundo de cosas. La objetificación y la mediatización se dan solo sí se paga el precio de un goce que deja atrás las pasiones, dando paso a unas redes múltiples de mediaciones de disfrute. El buen colono -invirtiendo las prácticas religiosas anteriores- debe ganarse para perderse en un mar de sensaciones que no son más que objetos dispuestos para un disfrute, irreversiblemente fugaz e instantáneo: el colonizado es el primer objeto de dichas prácticas.

Al Solidarismo lo constituyen un conjunto de prácticas que operan como mecanismo de sutura de las diferencias y desigualdades entre clases. Dichas prácticas se caracterizan entre otros rasgos por: invertir el lugar de lo colectivo y lo individual borrando sus diferencias, diluir los regímenes de responsabilidad social y reemplazarlos por ficciones culpabilizantes, dejar a los sujetos que reciben en situación iterativa de donatario, reemplazar la presencia estatal por la acción privada y re-inaugurar la filantropía y la beneficencia privada como mecanismos de atención de carencias.

La solidaridad naturalizada como potencia del que más tiene deviene solidarismo como exceso que da lugar a la anulación de sus propios fundamentos. Lo que es un resultado de las estructuración social (en tanto colectivo), la carencia, es in-vertida como consecuencia de una práctica individual suturada por otra acción individual de quien da. El solidarismo necesita de la aceptación de los sujetos de su estado de carencia y exige la ficcionalización de una culpa social sin responsables. Es en este contexto que la religión neo-colonial implica un proceso de redefinición de los contenidos y alcances de la filantropía como mecanismo social, que privatizando la desigualdad "elimina" la necesidad de intervención estatal.

La Resignación es una forma de aceptación naturalizada y hecha cuerpo de la imposibilidad de rupturar el mundo del No y las consecuencias de la no-verdad como régimen de adecuación de expectativas.

En el marco del capitalismo dependiente y colonial aparece la no-verdad como centro de gravedad de la subjetividad fetichizada. Emerge la consagración y naturalización de lo falso como condición social de posibilidad de la mercantilización de la vida vivida.

La vida cotidiana de los que viven en el mundo del "no" se cualifica por el contacto directo de la no-verdad de las fantasías del capital. No tener trabajo, no tener educación, no tener acceso a la salud se conectan directamente con las máximas del sistema tales como: "el que quiere trabaja", "el que se esfuerza logra lo que quiere".

Cuando los sujetos experiencian la falta como ligadura "normal" y diaria de su vida, los cielos prometidos por el mercado se des-hacen ante los ojos aceptadores de un 
cuerpo secuestrado en su propia materialidad de individuo. La vida se estructura por esta vía alrededor de esa no-verdad como anverso de una mentira sistemática: nadie es dueño de nadie. Cuando los ciudadanos del mundo del "no" viven, lo hacen en y por lo que les falta, pudiendo ver lo que son. Dada esta instancia, aquello que se piensa como objetivo vital naturalizado se vuelve esquivo y lejano.

Esa no-verdad comienza, a fuerza de repetición, a convertirse en centro de gravedad de la subjetividad por donde las múltiples figuras de los fantasmas se catalizan.

La no-verdad es escenificada como reverso necesario (y suturador) de la dominación al ponerse en estado de una narración que muestra la grafía de la acumulación y de los no; se muestra por-no-gráficamente. La grafía de la dominación se patentiza como aquello que, al verlo, es imposible de ser vivido sino como resignación a la identidad negada de la pluralidad de subjetividades posibles. Los sujetos de la dominación se ven así "no-más" con lo único que tienen: sus cuerpos expropiados y superfluos.

En este sentido, el Mundo del No anula el futuro en un permanente estar siempre del mismo modo, un proceso en permanente producción de coagulación de la acción.

Tal como en una unidad trinitaria los tres vértices de la religión aludida se entraman ocupando y torsionando en diversos sentidos sus lugares. Desde esta perspectiva, la lógica de la resignación es el punto de partida de la mimetización con el Otro que nos agrede y agrada desde el poder colonial. Tomando en cuenta otra banda de la compleja trama dialectizada, el consumo como marca identitaria (aquello que nos hace ser alguien) se conecta con el solidarismo como iteratividad de la falta (al único que beneficia es al que da) y la resignación como coagulación de la acción.

Ahora bien, esta religión neo-colonial por definición es una totalidad rasgada, y en sus intentos de presentarse como aquello que no posee una unidad externa que la niegue aparecen justamente los pliegues, quiebres y faltas instanciados en un conjunto de prácticas intersticiales.

\section{Prácticas intersticiales: reciprocidad, gasto festivo y esperanza \\ 4.1. Hacia una conceptualización de las prácticas intersticiales}

Como hemos afirmado ya existen en la "vida de todos los días" de los millones de sujetos expulsados y desechados del Sur Global pliegues in-advertidos, intersticiales y ocluidos. Se efectivizan así prácticas de la vida vivida en tanto potencia de la energías excedentes a la depredación. En este contexto aparecen en el horizonte de compresión, prácticas para las cuales la sociología no tiene -usualmente- un plexo crítico, conceptual y metodológico ${ }^{9}$ demasiado elaborado. Algunas de las prácticas aludidas

\footnotetext{
${ }^{9}$ Hemos propuesto algunas alternativas para analizar las sensaciones y la creatividad en Scribano, Adrián. (2008b) El Proceso de Investigación Social Cualitativo. Editorial Prometeo. ISBN 978-987-574-236-9 pag. 300 Buenos Aires y Scribano, Adrián. Conocimiento Social e Investigación Social en Latinoamérica. En Cohen, N.
} 
son la felicidad, la esperanza y el disfrute que de un modo u otro emergen como contracara de los ejes de la religión neo-colonial arriba enunciada.

Prácticas intersticiales son aquellas relaciones sociales que se apropian de los espacios abiertos e indeterminados de la estructura capitalista ${ }^{10}$ generando un eje "conductual" que se ubica transversalmente respecto de los vectores centrales de configuración de las políticas de los cuerpos y las emociones. Por lo tanto, no son prácticas ortodoxas ni son paradóxicas y tampoco heterodoxas en el sentido conceptual que les diera a estas Pierre Bourdieu.

Entre muchas maneras de entender conceptualmente qué significan las prácticas aludidas, mencionaremos aquí tres de ellas: como pliegues, como quiebres y como partes "no esperadas" de un puzzle.

Las prácticas intersticiales anidan en los pliegues inadvertidos de la superficie naturalizada y naturalizante de las políticas de los cuerpos y las emociones que supone la religión neo-colonial. Son disrupciones en el contexto de normatividad. Son emergencias que (rebelan y) se revelan respecto del vacío inercial al que limita el consumo mimético, al etiquetamiento de la imposibilidad al que condena la resignación y al encerramiento al que sirve el solidarismo.

Las prácticas a las que nos referimos se actualizan e instancian en los intersticios entendiendo a estos como los quiebres estructurales por donde se visibilizan las ausencias de un sistema de relaciones sociales determinado. Estos quiebres son espacios irregulares donde los sujetos construyen un conjunto de relaciones tendientes a soldar la estructura conflictual pero con estaños diferentes y múltiples. Soldaduras que atraviesan los cuerpos y la emociones potenciando los re-apasionamientos, uniendo con reciprocidad donde existía consumo mimético, conjugando el nosotros del gasto festivo donde había solidarismo y expandiendo la esperanza donde se daba la resignación.

Las prácticas intersticiales son partes "no esperadas" que aparecen asociadas pero no son parte del puzzle que conjugan al consumo mimético, el solidarismo y la resignación.

La metáfora pictórica del puzzle es una representación insuficiente pero "disparadora" para observar cómo en el marco de un conjunto de relaciones sociales hay otras que corresponden a la "entrancias" y "salencias" de lo que la figura insinúa. Lo intersticial entonces se adentra y sale del puzzle de modo contingente e indeterminado, pues depende de su configuración histórica estructural particular.

\footnotetext{
y J. I. Piovani (comps., 2008a), La metodología de la investigación en debate. Buenos Aires y La Plata: Eudeba - Edulp. P.P. 87-117.

10 Usamos aquí la expresión "estructura capitalista" conscientes de la necesidad de aclarar (tarea que no podemos realizar aquí) las diferencias estructurales dentro de dicha estructura.
} 


\section{Religión Neo-colonial y prácticas intersticiales ${ }^{11}$}

Una crítica a la trinidad colonial significa producir condiciones de observabilidad sobre las prácticas intersticiales aludidas e implica el siguiente recorrido dialéctico: a) del consumo mimético pasar a la observación del intercambio recíproco (más allá del capital social) y el don; ${ }^{12}$ b) del solidarismo pasar a la observación del gasto festivo ${ }^{13}$ y c) de la resignación pasar a la observación de la confiabilidad y la credibilidad $^{14}$ (como crítica sistemática a lo ideológico y re-semantización de la esperanza).

\begin{tabular}{|l|c|c|}
\hline $\begin{array}{l}\text { Trinidad Religión } \\
\text { Neo-colonial }\end{array}$ & $\begin{array}{c}\text { "Nuevos" Objetos } \\
\text { Sociológicos }\end{array}$ & $\begin{array}{c}\text { Prácticas Sociales por } \\
\text { Observar }\end{array}$ \\
\hline Consumo Mimético & Disfrute & Don - reciprocidad \\
\hline Solidarismo & Felicidad & Gasto Festivo \\
\hline Resignación & Esperanza & Confianza - Credibilidad \\
\hline
\end{tabular}

Las mismas subjetividades y sensibilidades tachadas, desechadas y expulsadas son el punto de giro que abre la compuerta para observar las voces polifónicas, la multiplicidad de torsiones corporales y diversidad de caminos que existen en los meandros de la dominación neo-colonial.

El don en tanto forma de intercambio implica todos aquellos modos de relaciones en los que los sujetos y los colectivos permutan bienes y recursos en condiciones de paridad $^{15}$. La traza que dejan las prácticas de dar y recibir que se realizan en tanto "puestas entre paréntesis" de la mercantilización propia de la estructura capitalista, son espacios de potencial disfrute. La re-construcción de las formas sociales del disfrute implica el paso por la crítica a la contención, regulación y apropiación de bienes y recursos. El ahorro ascético que nos impone la mirada modernizadora se liga con la lógica de la imposibilidad y se contrapone al gasto festivo en tanto derroche como práctica indócil.

El gasto festivo es el modo de reconversión de energías sociales y corporales que permiten abrir, expandir y multiplicar las potencialidades de los sujetos y los colectivos.

\footnotetext{
${ }^{11}$ Parte de los expuesto aquí resume lo que hemos publicado en Figari y Scribano 2009.

12 Para una visión, diversa a la aquí dada, pero muy interesante y original sobre el don en América Latina Cfr. Martins, P. H. y Campos, R. C. 2006.

${ }^{13}$ Una mirada disímil pero inspiradora sobre el papel del gasto festivo en la sensibilidad latinoamericana se puede encontrar en el ya clásico trabajo de Morande, P. 1983.

${ }^{14}$ En un sentido diferente pero que aquí se usa como plataforma conceptual para la noción de confianza Cfr. Giddens.

${ }^{15}$ Quiero expresar mi agradecimiento a mi colega y amigo Paulo Henrique Martins por sus sugerencias y motivación para volver analítica las prácticas de intercambio reciproco bajo la cobertura conceptual de la "teoría del don".
} 
La diversidad de maneras que adquieren las fiestas y los carnavales, instancia las formas sociales ritualizadas de felicidad.

Las creencias sociales son los actos de reconocimiento desde y sobre las sensibilidades colectivas y subjetivas que recusan y "tensionan" las políticas de los cuerpos y las sensaciones. Las fiabilidades que advienen por los sinuosos caminos de lo "inter-personal", por -y desde- las situaciones de co-presencia y como credibilidad colectiva, sientan las bases contra la resignación. La desconexión de sentido producida por la pérdida de valor político institucional de las imágenes del mundo basadas en narraciones religiosas urge a revisar las maneras de conservación de credibilidad existentes. La esperanza ${ }^{16}$ anida en las prácticas anticipatorias de las felicidades cotidianas que se entremezclan con las fatalidades que augura la resignación.

En la lógica tensional del gasto festivo con el consumo mimético aparece otro campo de la disposición mobesiana que opera intersticialmente: la destrucción. El acto de consumo de un bien o recurso en contextos festivos involucra la apropiación por eliminación de su carácter mercantil. Por esta vía aquello que se liga desde y a través de los dispositivos de regulación de las sensaciones con la fetichización y mercantilización de la vida encuentra su opuesto dialéctico (y superador).

Desde la fiabilidad que generan las formas sociales del amor se resemantizan las energías corporales y sociales que involucran los actos de anulación del otro por apropiación de su "goce" (sensu Marx). El placer no es solo una de las tecnologías sociales de constitución de subjetividades (in)adecuadas, sino un campo de expresión del re-apasionamiento de la vida social.

Es en las tensiones y contradicciones entre rasgos de la religión neo-colonial y prácticas intersticiales que se juega las nuevas torsiones de las bandas mobesianas de la estructuración del capitalismo como religión.

En estas contradicciones puede observarse la aparición de una equivalencia que, a nuestro criterio, es una de las huellas centrales para comprender el mundo del siglo XXI: las equivalencias entre hombre de fe y hombre de consumo.

\section{Fe, consumo y política en el siglo XXI: hombre religioso y hombre consumidor}

Al igual que la necesidad de exponer las razones que teníamos para considerar la pertinencia de la identificación y selección como objeto de estudio a la religión neocolonial, se vuelve necesario insistir en la importancia sobre los paralelismo entre hombre de fe y hombre de consumo en el siglo XXI. Existen varias razones que muestran y avalan la relevancia que señalamos; aquí solo subrayamos cuatro:

\footnotetext{
${ }^{16}$ Más allá de las diferencias que se pueden observar la preocupación por volver reflexiva la problemática de la esperanza se sitúa en la línea inspirada en los trabajos de Ernst Bloch.
} 
1. Es verdad que el capitalismo ha estado atado al consumo desde sus orígenes y que la denominada sociedad consumista fue llevada a su paroxismo en las llamadas sociedades post-materiales. Lo que aquí se busca enfatizar es que las políticas de vida, las experiencias interiores y la intimidad no son ya solamente objeto de compra/venta, sino que el régimen de sensibilidad está adquiriendo el estatus público de creencia religiosa. Desde el "Yes, we can" hasta el "Milanesas para todos" se regeneran dispositivos de regulación de las sensaciones que en su impronta afectiva-cognitiva elaboran un registro público de la subjetividad mixtificada y mistificada de la participación en una totalidad hipostasiada a través del consumo.

2. También es cierto que los procesos de abstinencia y ahorro ascético han atravesado la entera historia del capitalismo y que sus reversos, como la transgresión y el despilfarro, han ocupado también un lugar central en su reproducción. En la situación actual es la estructura sacrificial en tanto forma la que cobra relevancia. El sacrificio no ya como esfuerzo individual/colectivo para vencer la escasez, ni como parámetro para los intercambios recíprocos es puesto en el centro de la escena de la vida cotidiana como rito por el cual se enhebran expiación de culpas, participación mística en/de la totalidad y muerte. Traspasando sus sentidos anteriores, el capitalismo ha vaciado el significado de la muerte redefiniéndola como sacrificio necesario y constituyente de la reproducción de la vida en el consumo. Las víctimas de la estructura sacrificial se transforman en mediaciones para la reproducción de la vida, una vida vivida al borde de la muerte. Estas víctimas son tanto los miles de millones de seres humanos que experiencian la expulsión y la desposesión, como los activos ambientales que son depredados en la pira sacrificial del progreso entendido como ampliación del consumo de unos pocos.

3. En la misma dirección, los procesos de crisis y metamorfosis del capitalismo han estado asociados a la puesta en escena y espectacularidad. Desde la Feria de París de 1910 pasando por las concentraciones hitlerianas hasta llegar a los lanzamientos de la NASA, el capitalismo siempre ha mostrado su poder en espectáculos públicos. Hoy en la era de Internet y las transmisiones en vivo para miles de millones de sujetos la espectacularización toma (y re-toma) otros rasgos para ganar su importancia y centralidad. Todo lo que es vivenciado debe ser representado en público, transmitido masivamente y reconocido/aprobado por "muchos". La cotidianidad del espectáculo implica el surgimiento de una espiritualidad "reality show", donde las distancias entre el Gran Hermano y los sujetos que miran se anulan en consonancia directa con lo que hemos sostenido aquí arriba en 1 .

4. En consonancia y como consecuencia de lo expuesto, unos de los rasgos más importantes de la actual metamorfosis del capitalismo lo constituye en re- 
transformarse en una Economía Cúltica. Es decir, la estabilización de la tasa de ganancias de las megacorporaciones tiene en la sacrificialidad espectacular de las vidas expuestas y coaguladas no solo un "lugar" asegurado para seguir reproduciéndose, sino también la modificación más adecuada en su economía política de la moral.

Intimidades en venta, totalidades teatralizadas, individuos y activos ambientales enviados a las hogueras y altares sacrificiales del progreso, prácticas de consumo vueltas decálogos para la acción son solo algunas de las consecuencias de las modificaciones y re-elaboraciones de la religión neo-colonial en tanto estructura de la actual economía política de la moral.

\section{BIBLIOGRAFÍA}

Bataille, G. (1991) "Teoría de la Religión" Taurus. Madrid.

Baudrillard, J. (1991) "La transparencia del Mal" Anagrama Barcelona.

Benjamin, W. (1991) "Kapitalismus als Religion [Fragment]", in: Gesammelte Schriften, Hrsg.: Rolf Tiedemann und Hermann Schweppenhäuser, 7 Bde, Frankfurt am Main: Suhrkamp, 1. Auflage, Bd. VI, S. 100-103., 690-691.

Durkheim, E. (1983) "Las formas elementales de la vida religiosa". Ed. Colofón, México, D. F.

Durkheim, E. (1972) "La educación moral", Ed. Schapire, Bs. As.

Fromm, E. (1977) "Avere o essere?" Modadori Editore. Milano, Italia.

Marx, C. 2001 (1867) El Capital. Tomo I FCE. México. DF.

Marx, C. 1974 (1844) Manuscritos : Economía y Filosofía. Alianza. Madrid.

Scribano, A. $\left(2013^{a}\right)$ (Comp.) Teoría Social, Cuerpos y Emociones Estudios Sociológicos Editora. Pág. 195. Bs. As.

Scribano, A. (2013b) "Una Sociología de los cuerpos y la emociones desde Carlos Marx" en Scribano (Comp.) Teoría Social, Cuerpos y Emociones Estudios Sociológicos Editora. ISBN 978-987-28861-4-1 Pág. 195. Bs. As.

Scribano, A. (2013c) "Cuerpos y Emociones en El Capital" Revista Nómadas. Universidad Central. Bogota. Colombia. N. ${ }^{\circ} 38$ en prensa.

Scribano, A. (2012 $)$ Teorías sociales del Sur: Una mirada post-independentista. Buenos Aires, ESEditora. ISBN 978-987-26922-9-2 - E-Book Córdoba: Universitas Editorial Científica Universitaria. ISBN 978-987-28861-0-3 pág. 230.

Scribano, A. (2012b) "Prólogo. El Capitalismo como Religión y Segregación Racializante: dos claves para leer las fronteras de la gestión de las emociones", en Iván Pincheira (Coord.): Archivos de Frontera. El gobierno de las emociones en Argentina y Chile del presente, ISBN 978-956-9065-18-7, Santiago de Chile, Editorial Escaparate, pp. 13-25. 
Scribano, A. (2012c) "Sociología de los cuerpos/emociones" Revista Latinoamericana de Estudios sobre Cuerpos, Emociones y Sociedad. N. ${ }^{\circ}$ 10. Año 4. Diciembre 2012marzo de 2013. Argentina. ISSN: 1852-8759. pp. 91-111. http://www.relaces.com.ar/index.php/relaces/article/view/224/143

Scribano, A. (2012d) "Cuerpos, Emociones y Sociedad: Una lectura desde Walter Benjamin" Dossiê Sociologia e Antropologia dos Corpos e das Emoções da RBSE - Revista Brasileira de Sociologia da Emoção, vol. 11, N. ${ }^{\circ}$ 33, de dezembro de 2012 ISSN 1676-8965, Paraiba, Brasil, p.p 674-696.

Scribano, A. (2010a) "Cuerpo, Emociones y Teoría Social Clásica. Hacia una sociología del conocimiento de los estudios sociales sobre los cuerpos y las emociones" En José Luis Grosso y María Eugenia Boito. (Comp.) Cuerpos y Emociones desde América Latina. CEA-CONICET. Doctorado en Ciencias Humanas. UNCa. pp. 15-38.

Scribano, A. y Figari, C. (2009) "Cuerpo(s), Subjetividad(es) y Conflicto(s) Hacia una sociología de los cuerpos y las emociones desde Latinoamérica" 978-987-9355-91-6 CLACSO-CICCUS.

Weber, M. (1963) The Sociology of Religion, Beacon, Boston.

Weber, M. (1990) Economía y Sociedad. FCE, Méjico, D. F. 